Institute of $\mathbf{F}_{\text {ood and }} \mathbf{A}_{\text {gricultural }} \mathbf{S}_{\text {ciences }}$

\title{
Manual de los Reglamentos del Agua de Florida: Introducción ${ }^{1}$
}

\author{
Michael T. Olexa, Laura Minton, Dulcy Miller, y Sarah Corbett ${ }^{2}$
}

\section{Agradecimientos}

Los autores agradecen a Richard Budell de la Oficina de Política del Agua Agrícola del Departamento de Agricultura y Servicios al Consumidor de Florida. Los autores también agradecen a David H. Hammonds, Consultor del Programa de Salud Ambiental, Oficina de Programas de Aguas de Drenaje en el Sitio, del Departamento de Salud de Florida, y a Edward A. Bettinger, Consultor del Programa de Salud Ambiental, Oficina de Programas de Agua del Departamento de Salud de Florida.

\section{Propósito General}

Este manual esta diseñado como una brújula para moverse a través de la red intrincada de estatutos, reglamentos y responsabilidades potenciales que identifican al complejo actual de leyes para protección del agua. Fue creado para lectores sin experiencia en leyes y como un primer paso necesario para identificar que actividades agrícolas ameritan atención especial, debido a las implicaciones que tienen respecto a aguas subterráneas y superficiales. También proporciona una introducción al lector para que conozca las principales agencias y estatutos que gobiernan el área de la protección del agua.

1. Este es el documento EDIS FE063, una publicación del Department of Food and Resource Economics, Florida Cooperative Extension Service, Institute of Food and Agricultural Sciences, University of Florida, Gainesville, FL. Publicada Noviembre 2002. Por favor visite la página electrónica EDIS en http://edis.ifas.ufl.edu.

2. Michael T. Olexa, es profesor del Department of Food and Resource Economics, Florida Cooperative Extension Service, Institute of Food and Agricultural Sciences, University of Florida, Gainesville, FL; y miembro de Florida Bar; Presidente de Agricultural Law Committee of The Florida Bar; y Director del Agricultural Law Center. Laura Minton, Dulcy Miller, y Sarah Corbett son estudiantes graduadas de Levin College of Law, University of Florida, Gainesville, FL. Filiberto Reyes-Villanueva fue el traductor de la versión en ingles al español.

Esta publicación esta diseñada para proporcionar información precisa, actualizada y autorizada sobre esta material. Sin embargo, ya que las leyes, reglas administrativas y decisiones de la corte, sobre las cuales están basados, están sujetas a revisión constante; algunas partes de esta publicación podrían ser obsoletas en cualquier momento. Esta publicación es distribuida bajo el entendimiento que los autores no están involucrados en ninguna representación legal u otros servicios profesionales, y que la información contenida aquí no debe ser considerada como un substituto de una asesoria legal. Esta publicación no esta completa en proporcionar toda la información para lograr el cumplimiento de las leyes y reglamentos que gobiernan la protección del agua. Por estas razones, el uso de estos manuales por cualquier persona constituye un acuerdo para mantener libre de daño a los autores, al Florida Cooperative Extension Service, al Institute of Food and Agricultural Sciences, y a la University of Florida por cualquier demanda por responsabilidad de daños, o gastos en que pueda incurrir cualquier persona, como un resultado de hacer referencia o confianza sobre la información contenida en esta publicación. Esta publicación fue apoyada financieramente por el Florida Department of Agriculture and Consumer Services.

EI Instituto de Alimentos y Ciencias Agrícolas es Un empleador que opera bajo Acción Afirmativa y provee Oportunidades Igualitarias, dedicado a promocionar la investigación, a información educativa y otros servicios, únicamente a los individuos e instituciones que operan baj discriminación sin considerar color, raza, sexo, edad, incapacidad u origen. Para más información sobre como obtener otras publicaciones de la extensión, comuníquese con la oficina de Servicio de Extensión de su condado. Servicio de Extensión de la Florida / Instituto de Alimentos y Ciencias Agrícolas / Universidad de la Florida / Christine Taylor Waddill, Decana. 
La ley en esta área esta evolucionando rápidamente en la medida en que se incrementa el interés por el medio ambiente. Debido a que varían las fuentes y los objetivos de los estatutos ambientales existentes, la ley como un todo no se ha desarrollado con precisión sistemática. Esta presenta una lista confusa de reglamentos sobrepuestos, ambiguos y aún contradictorios.

Consecuentemente, esta área de la ley es una barrera formidable tanto para los abogados como para las personas inexpertas que luchan para determinar sus derechos exactos y responsabilidades. La perseverancia es necesaria, aunque también los castigos u obligaciones pueden ser muy importantes en algunos casos.

Este trabajo no debe ser considerado como la última palabra sobre cualquiera de los tópicos discutidos, porque un estudio completo de esta área está más allá del alcance de esta publicación. Mas bien, el lector debe ver esta publicación como un medio para determinar las áreas en donde debe buscar mas información, y como un breve directorio de las agencias que pueden proporcionar respuestas a preguntas más específicas. Las agencias estatales y federales son incuestionablemente las instituciones ideales para preguntas específicas, ya que ellas están en contacto directo con las consideraciones tanto formales como prácticas que ellas regulan.

Por consecuencia, al final de cada subsección de "Actividades Reguladas" hay códigos de Contactos de Información, que se refieren a las direcciones y/o números telefónicos de las agencias y divisiones enlistadas en el Apéndice. Estas agencias pueden proporcionar más información sobre el tópico, contestar preguntas específicas y a menudo proveer literatura gratuita.

La efectividad de esta publicación solo puede ser mejorada, mediante la aportación de ideas y sugerencias acerca del enfoque y calidad de su cobertura. Los comentarios sobre cualquiera de las áreas que puedan haberse omitido, pero que ameritan su inclusión, serían particularmente valorados. La retroalimentación desde el lector es un ingrediente necesario para completar cualquiera de las ediciones futuras exitosas. Con esto en mente, por favor envíe cualquier comentario o sugerencia a la siguiente dirección:

Michael T. Olexa, PhD, JD

Post Office Box 110240

University of Florida

Gainesville, Fl 32611-0240 